
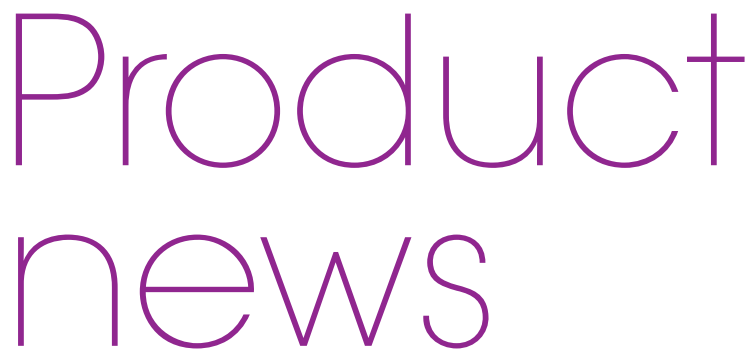

Product news is provided as a service to readers using text and images from

the manufacturer, supplier or distributor and does not imply endorsement

by BDJ Team. Normal and prudent research should be exercised before

purchase or use of any product mentioned.

\section{NEW MINERALISING FLUORIDE-FREE TOOTHPASTE LAUNCHED}

A new fluoride-free toothpaste, formulated to adhere to the tooth surface and slowly release calcium and phosphate ions, has been launched by BioMin Technologies.

BioMin C, which helps replace lost minerals from tooth surfaces, is designed for those who for a variety of reasons do not wish to use fluoride-containing products but still want to have the benefits of a protective toothpaste. It is also designed for those parts of the world where high levels of fluoride are naturally present in the water supply.

This launch follows the successful introduction of BioMin $\mathrm{F}$ - the slow release fluoride version - in April 2016 with BioMin C now being available through dental practices and online. The new toothpaste contains a patented calcium chlorophosphosilicate that releases chloride ions as opposed to fluoride ions. Chloride ions are

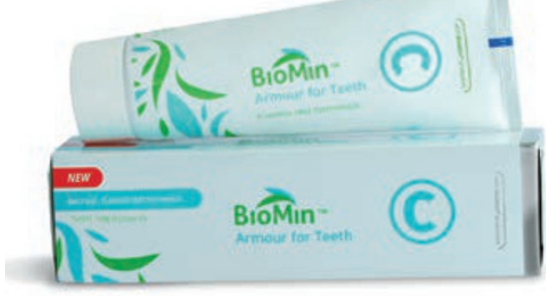

already present in all body fluids.

In addition to remineralising tooth surfaces, the new BioMin C toothpaste may help protect teeth, reduce sensitivity and diminish the risk of initial tooth decay.

BioMin C has been developed as a result of extensive research undertaken at Queen Mary University of London in recent years. Over $65 \%$ of BioMin F test evaluators suffering from tooth sensitivity reported a significant reduction in sensitivity and $15 \%$ claimed to be symptom free after two weeks of use.

BioMin $\mathrm{F}$ is now available in more than 13 countries. www.biomin.co.uk

\title{
ASSURED QUALITY MANAGEMENT SYSTEM
}

Being able to offer an assured quality management system is critical when dealing with medical devices, such as handpieces or small equipment products, and related repairs or services. For many years, B.A. International has been certified to ISO $13485: 2008$, the quality management system for medical devices. B.A. International is unique in offering full accountability for products and services provided, giving total peace of mind to all its customers.

Total Care Solutions means that one simple fixed monthly payment provides handpieces, maintenance and any potential repair. Total Care Solutions means not having to worry about anything relating to your handpieces whilst under contract.

Trusted Value Solutions offers handpieces and small equipment at incredible value and

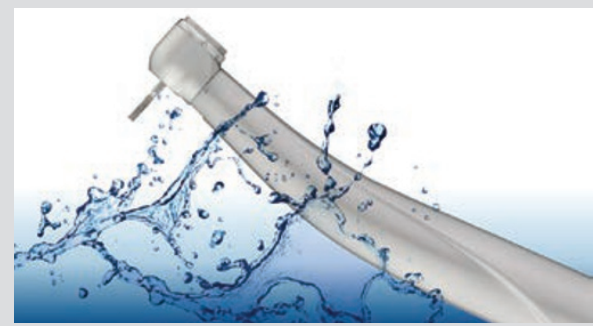

repairs at lowest possible prices. Complying with all regulations applicable to these medical devices is a given. Not only that, but B.A. stands behind any products offered for years to come. Trusted Value is the assurance of remaining risk free.

Twenty-four hours repair turnaround times, direct communication with the B.A. technician and repairs to any budget are all part of the B.A. International offering.

https://www.bainternational.co.uk

\section{REVITALISE YOUR PATIENT DENTAL CHAIRS}

Meditelle-Dental provides a professional onsite re-covering service to rejuvenate your dental patient chairs at your surgery.

This onsite service covers the whole of the UK and specialises in the reupholstering of most makes and models of patient dental chairs. All procedures are carried out at your premises ensuring your equipment is not out of service for any length of time, minimising disruption and downtime. Flexible appointments and early time slots prior to opening are offered to work around your practice's schedule.

Meditelle's re-covering service will keep your patient chairs hygienic and ensure that the safety of your equipment is maintained. Re-upholstering may be all that's required if you have any scuffs, slits or tears in your dental chair vinyl that could present an infection control hazard.

Meditelle uses hydrophobic, antimicrobial medical grade vinyls which are MRSA and E-coli resistant and offered in a wide range of colours.

Offered in conjunction with this specialist service are the additional options of having a made-to-measure foot guard fitted and your operator stools re-covered to match your revitalised dental chair.

Obtaining a no-obligation quotation couldn't be easier, just email a full image of your chair front and back to Meditelle along with your postcode.

Telephone 0121332 1850, email enquiry@meditelle.co.uk or visit www. meditelle-dental.co.uk.

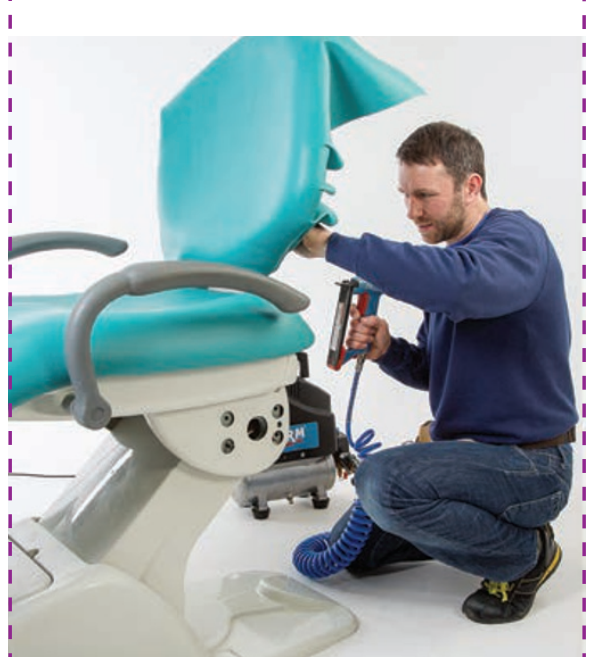

